\title{
Mechanism of the Rhodium-Catalyzed Hydroformylation of 4-(1-phenylvinyl)pyridine: A Detailed Computational Investigation of the Regioselectivity and Chemoselectivity
}

\author{
Xiaoling Luo ${ }^{1,2, a}$ and Rong Chen ${ }^{1, b}$ \\ ${ }^{1}$ College of chemistry, Chongqing Normal University, Chongqing, China, 400047 \\ 2Department of Chemistry and Chemical Engineering, Chongqing University, Chongqing, China, \\ 400047 \\ axiaolingluo@cqnu.edu.cn, brongchen@cqnu.edu.cn
}

Keywords: Hydroformylation, Hydrogenation, DFT, Chemoselectivity, Regioselectivity

\begin{abstract}
The mechanism of 4-(1-phenylvinyl)pyridine hydroformylation with $\mathrm{HRh}(\mathrm{CO})\left(\mathrm{PH}_{3}\right)_{3}$ as active catalyst has been proposed and discussed by B3LYP. Also, the regioselectivity and chemoselectivity are investigated by calculations and excellent agreement with the existing experimental results is displayed. It is found that the characteristic catalytic cycle is similar to that for olefin hydroformylation: (a) 4-(1-phenylvinyl)pyridine coordination and insertion, (b) CO coordination and insertion, and (c) $\mathrm{H} 2$ oxidative addition as well as aldehyde elimination. The rate-limiting and regioselectivity- determining step are $\mathrm{H}_{2}$ oxidative addition which determines the linear aldehyde product energetically. The competitive hydrogenation is along with (a) 4-(1-phenylvinyl)pyridine coordination and insertion, (b) $\mathrm{H}_{2}$ oxidative addition followed by hydrogenation product elimination Interestingly, $\mathrm{CO}$ coordination is found to be an exothermic $(\Delta \mathrm{H}<0)$ but endergonic $(\Delta \mathrm{G}>0)$ process, while the corresponding $\mathrm{H}_{2}$ process is endergonic and endothermic $(\Delta \mathrm{H}>0), \mathrm{H} 2$ is not competitive with $\mathrm{CO}$ from the viewpoint of thermodynamics. But hydrogenation is computed to be more favored than hydroformylation actually, so it can be conclude that the chemoselectivity is controlled by kinetics, not thermodynamics.
\end{abstract}

\section{Introduction}

Since its discovery by Roelen in 1938, hydroformylation, which converts olefins and synthesis gas $\left(\mathrm{H}_{2}+\mathrm{CO}\right)$ into aldehydes, has developed into an extremely important industrial process. Therefore, extensive studies have focused on the hydroformylation ${ }^{[1]}$ of olefin especially the asymmetric hydroformylation ${ }^{[2-6]}$.

Table1 Hydroformylation of vinylpyridines catalyzed by rhodium complexes ${ }^{[4]}$

\begin{tabular}{l|l|l|l|l|l|l}
\hline substrates & $\begin{array}{l}\text { Catalytic } \\
\text { precusor }\end{array}$ & solvent & $\begin{array}{l}\text { Conv. } \\
(\%)\end{array}$ & $\begin{array}{l}\text { Hydrogenation } \\
\text { yield(\%) }\end{array}$ & $\begin{array}{l}\text { Aldehyde } \\
\text { yield(\%) }\end{array}$ & b/n \\
\hline & $\mathrm{HRh}(\mathrm{CO})\left(\mathrm{PPh}_{3}\right)_{3}$ & benzene & 95.4 & 10.6 & 84.8 & $95 / 5^{[4 \mathrm{c}]}$ \\
\hline $\mathrm{HRh}(\mathrm{CO})\left(\mathrm{PPh}_{3}\right)_{3}$ & benzene & 41 & 5 & 36 & $32 / 68^{[\mathrm{dd}]}$ \\
\hline
\end{tabular}

From 1991 to 1997 , Botteghi C. et al. ${ }^{[4]}$ have studied the rhodium-catalyzed hydroformylation of vinyl-pyridine derivatives experimentally and have found some interesting results as shown in Table 1. And these results were reproduced by Aldo, C et al. and Raffaello, L et al. ${ }^{[5]}$ in 2000 and 2005, and they presented the evidence for the observed different chemo- and regioselectivities. The basic hydroformylation catalytic cycle comprised of olefin coordination and insertion, $\mathrm{CO}$ coordination and insertion, and $\mathrm{H}_{2}$ oxidative addition as well as aldehyde elimination, is based on the Wilkinson ${ }^{\text {[7] }}$ 
mechanism. Although it is intuitive to consider vinyl-pyridine derivatives to have mechanistic aspects in hydroformylation similar to those of olefins without pyridinal substituent group ${ }^{[8]}$, some important differences must exist, arising from the individual characters of pyridinal substituent group and the unusual chemoselectivity need to be elucidated. More important, whether and how the position of the nitrogen atom with respect to the olefin double bond affects the region- and chemoselectivity need to be answered finally after a series of studies. These results would be an important, theoretical complementarity of understanding of vinyl-pyridine derivatives hydroformylation and might be useful to experimentalists for explaining these interesting phenomena in experiments and inventing more effective method to synthesize desired aldehyde products or hydrogenation products.

\section{Computational Details}

The $\mathrm{PPh}_{3}$ ligands in the catalytic precursor $\mathrm{HRh}(\mathrm{CO})\left(\mathrm{PPh}_{3}\right)_{3}$ are modeled as $\mathrm{PH}_{3}$ to minimizing computing time. All geometry optimizations and frequency calculations were performed with the B3LYP ${ }^{[9]}$ functional implemented in Gaussian 09. The LANL2DZ ${ }^{[10]}$ basis set was used for rhodium and phosphorus. The $6-31 \mathrm{G}(\mathrm{d}, \mathrm{p})$ basis set was used for other atoms. The harmonic vibrational frequencies were also calculated at the same level to characterize the nature of the stationary points as true minima with no imaginary or transition states with only one imaginary frequency and to provide thermodynamic quantities such as thermal corrections to energy, enthalpy, and Gibbs free energy. All free energies reported are Gibbs free energies involving zero-point vibrational energy corrections, thermal corrections at $298 \mathrm{~K}$, and single point solvation free energy corrections computed by using the $\mathrm{CPCM}^{[11]}$ polarizable conductor calculation model as implemented in Gaussian 09.

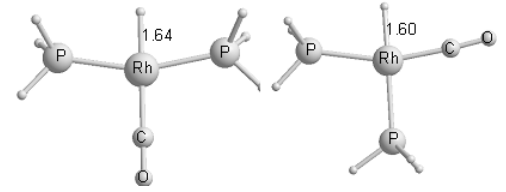

Scheme 1 The Modeled Active Catalyst

\section{Results and Discussion}

The potential energy surface (given in Figure 1) of 4-(1-phenylvinyl)pyridine hydroformylation was fully investigated by discussing a series of reasonable structures of intermediates and transition states following the Wilkinson mechanism. Subsequently, the hydrogenation of 4-(1-phenylvinyl)pyridine to 4-(1-phenylethyl)pyridine, the key competitive reaction, was studied to clarify the chemoselectivity.
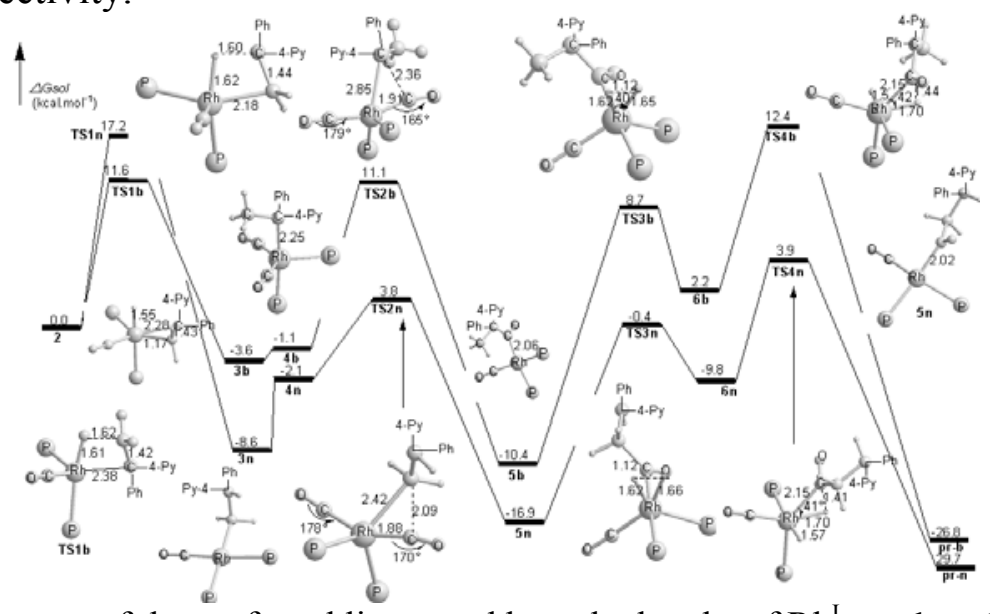

Fig 1. Free energy diagram of the preferred linear and branched paths of $\mathrm{Rh}^{\mathrm{I}}$-catalyzed hydroformylation of 4-(1-phenylvinyl)pyridine. Calculated at the B3LYP/LANL2DZ+6-31G** level with CPCM (benzene) single point solvation energy correction. 
Initial from the dissociation of one $\mathrm{PH}_{3}$ ligand from the original catalyst $\mathrm{HRh}(\mathrm{CO})\left(\mathrm{PH}_{3}\right)_{3}$ to give birth to active catalyst $\mathrm{HRh}(\mathrm{CO})\left(\mathrm{PH}_{3}\right)_{2}, 1$ which has two isomers(scheme 1). It is known that a square-planar $\mathrm{Rh}^{\mathrm{I}}$ complex is vulnerable to electrophilic attack from the perpendicular position, so the first key step of 4-(1-phenylvinyl)pyridine hydroformylation is coordination to form $\eta^{2}$-olefin adducts 2 and insertion into Rh-H bond. The structures of transition states and some other critical points associated with this step are illustrated in Figure 1 and Figure 2. The letter $\mathbf{n}$ in nomenclature of all the complexes denotes linear product while b denotes branched product, letter c remarks carbonyl ligand towards the vinyl while $\mathbf{p}$ remarks $\mathrm{PH}_{3}$ ligand and vinyl have opposite position, and $\mathbf{r}$, $\mathbf{s}$ refers to enationselectivity resulted from different relative position of phenyl and pyridinal.

Then the $\mathrm{C}=\mathrm{C}$ bond insertion into $\mathrm{Rh}-\mathrm{H}$ bond via transition states TS1 to generate 16-electron unsaturated complexes 3 . Because the axial hydride could bend towards either the $\alpha-C$ or $\beta-C$ of $C=C$, so there are 8 isomers of TS1, shown clearly in Figure 2. This step is indicated to be reversible by which the moderate activation free energy for both forward and back reaction and it differs from olefin without pyridinal substituent group hydroformylation using modified Rh catalysts.

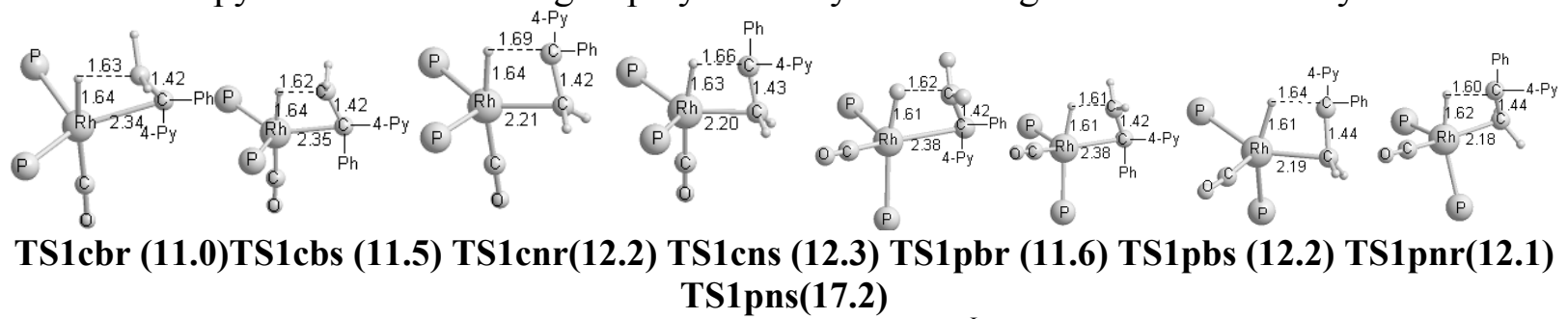

Fig 2. Possible vinyl insertion transition states for the $\mathrm{Rh}^{\mathrm{I}}$-catalyzed hydroformylation of 4-(1-phenylvinyl)pyridine. $\Delta G^{\neq}\left(\mathrm{kcal}_{\mathrm{mol}}{ }^{-1}\right)$ is activation free energy.

Followed, carbonyl inserts into Rh- alkyl bond via TS2 to form four-coordinated intermediates 5 with the most stable one is $\mathbf{5 p n s}$. This step is predicted to be reversible too and also exothermic by 4.2 11.5 kcal.mol ${ }^{-1}$. As shown in Figure 3, bending of the axial alkyl towards the equatorial carbonyl and the oxygen atom of the carbonyl in transition states are attributed to decrease the steric and electronic repulsion. The optimized geometries indicate that this step is actually completed by alkyl migration. The distance between $\mathrm{C} 1$ and $\mathrm{C} 2$ in linear isomers is obviously shorter than that of branched isomers as well as the $\Delta G^{\neq}$for linear path lower than that of branched path. And the preferred one is TS2pnr.

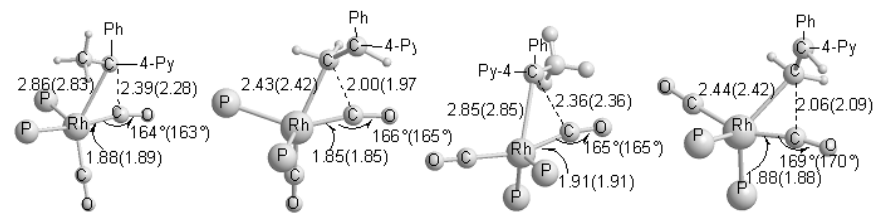

\section{TS2cbr(TS2cbs) TS2cnr(TS2cns) TS2pbr(TS2pbs) TS2pnr (TS2pns)}

$\Delta G^{\neq}=15.7(14.8) \quad \Delta G^{\neq}=9.2(10.5) \quad \Delta G^{\neq}=14.7(13.5) \quad \Delta G^{\neq}=7.9(14.2)$

Fig 3. Optimized CO insertion transition states for the $\mathrm{Rh}^{\mathrm{I}}$-catalyzed hydroformylation of 4-(1-phenylvinyl)pyridine. $\Delta G^{7}$ is activation free energy, kcal.mol ${ }^{-1}$.

Oxidative addition of $\mathrm{H}_{2}$ to $\mathbf{5}$ to give rise to a dihydrides acyl species $\mathbf{6}$ via transition states TS3 followed by a reductive elimination of the aldehyde via TS4 and the active catalyst 1 regeneration. The configuration of TS3 and TS4 is similar to that of hydrogenation given in Figure 5. Finally, one hydrid migrates onto the carbon atom of the acyl in complexes 6 to give birth to the four possible hydroformylation products and the catalytic cycle of 4-(1-phenylvinyl)pyridine hydroformylation is completed. The energy barrier for this step is generally feasible whereas that of back reaction is so high $\left(33.6 \sim 50.8 \mathrm{kcal}^{\mathrm{mol}}{ }^{-1}\right)$ thus it is considered to be irreversible. 


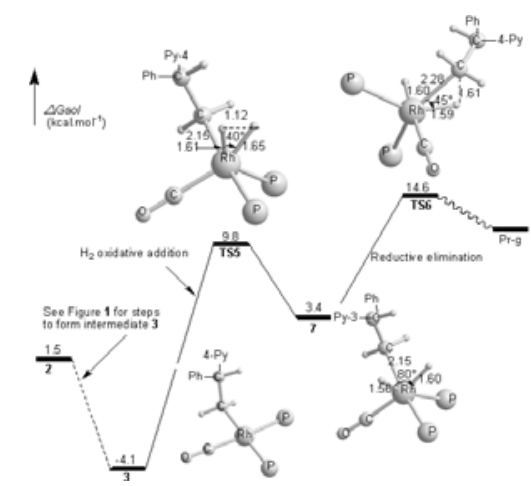

Fig 4. Free energy diagram of the preferred path of $\mathrm{Rh}^{\mathrm{I}}$-catalyzed hydrogenation of 4-(1-phenylvinyl)pyridine. Calculated at the B3LYP/LANL2DZ+6-31G** level with CPCM (benzene) single point solvation energy correction.

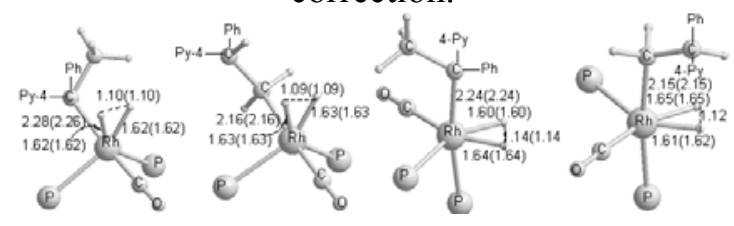
TS5cbr(TS5cbs)
TS5enr(TS5cns)
TS5pbr(TS5pbs)
TS5pnr (TS5pns)
$\Delta G^{\neq}=22.5(21.9)$
$\Delta G^{\neq}=15.5(19.4)$
$\Delta G^{\neq}=20.7(19.8)$
$\Delta G^{\neq}=13.9(18.5)$

Fig 5. Optimized $\mathrm{H}_{2}$ oxidative addition transition states for the $\mathrm{Rh}^{\mathrm{I}}$-catalyzed hydrogenation of 4-(1-phenylvinyl)pyridine. $\Delta G^{\neq}$is activation free energy, $\mathrm{kcal}^{\mathrm{mol}}{ }^{-1}$.

Hydrogenation mechanism: the catalytic cycle proceeds along with $\mathrm{H}_{2}$ oxidative addition to 3 to give rise to a dihydrides acyl species 7 via transition states TS5 followed by hydrogenated product elimination via TS6. The preferred hydrogenation path is given in Figure 4. The optimized geometries and activationg free energy of these transiton states are provided in Figure 5. As shown in Figure 3, There are eight pathways for $\mathrm{H}_{2}$ oxidative addition step and the most stable transition states is TS5pnr( equal to TS5 in Figure 4). The geometry parameters for all isomers are similar and the energy barrier of linear isomers (without methyl) is generally lower than that of branched isomers (with methyl). In the last step, one hydrid in dihydrides acyl species 7 migrates to acyl and the hydrogenation product 4-(1-phenylethyl)pyridine is gained with the catalyst 1 regenerated. Alike hydroformylation, there are 12 reductive elimination transition states (Figure 6 ) in all. The $\Delta G^{\neq}$of preferred one for this step is $9.1 \mathrm{kcal}^{\mathrm{mol}}{ }^{-1}$, lower than that of preceding step. So $\mathrm{H}_{2}$ oxidative addition is the rate-controlling step for whole hydrogenation cycle.

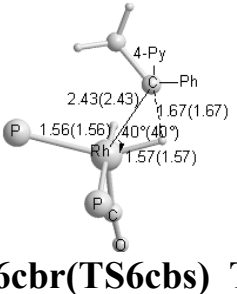

TS6cbr(TS6cbs)

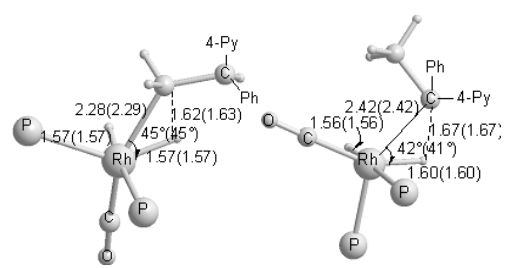

?

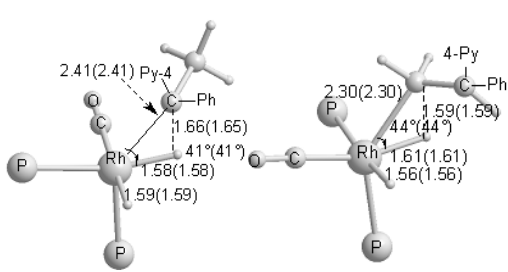

e

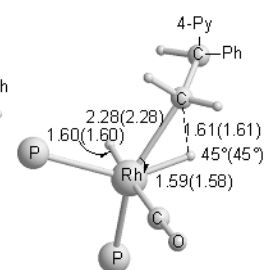

(TS6pnsc) TS6pnrp (TS6pnsp)

$$
\Delta G^{\neq}=9.1(9.3) \quad \Delta G^{\neq}=12.3(12.4) \Delta G^{\neq}=11.7(11.3) \quad \Delta G^{\neq}=9.2(10.1) \Delta G^{\neq}=13.2(13.2) \quad \Delta G^{\neq}=11.2(11.0)
$$

Fig 6. Optimized reductive elimination transition states for the $\mathrm{Rh}^{\mathrm{I}}$-catalyzed hydrogenation of 4-(1-phenylvinyl)pyridine. $\Delta G^{\neq}$is activation free energy, kcal.mol ${ }^{-1}$.

Chemoselectivity and regioselectivity From above mechanism analysis, it is known that the origin of chemoselectivity stems from unsaturated 3 since $\mathrm{CO}$ and $\mathrm{H}_{2}$ both can occupy the vacant site of 3. Although the energy barrier of $\mathrm{CO}$ addition and insertion step is calculated to be lower than that of $\mathrm{H}_{2}$ oxidative addition (Figure 3 and Figure 5), the chemoselectivity is not determined here beacuse $\mathrm{CO}$ insertion is neither irreversible nor the rate- determining. The final reductive elimination step is predicted to be irreversible, but it lies behind $\mathrm{H}_{2}$ oxidative addition. And our theoretical study on the catalytic cycle indicates that $\mathrm{H}_{2}$ oxidative activation (TS2 and TS6) is the rate-determining step. So 
this step is also chemoselectivity- determining step. Comparison of the lowest activation free energy of TS2 and TS6 (Figure 1 and Figure 4) indicates that hydrogenation is favored by $2.6 \mathrm{kcal}^{\mathrm{mol}}{ }^{-1}$. This result well corresponds to the observed experimental data in Table 1.

The regioselectivity stems from $\mathrm{C}=\mathrm{C}$ bond insertion into $\mathrm{Rh}-\mathrm{H}$ bond step. Shown obviously in Figure 2, when the axial hydrogen bonds with the unsubstituted carbon, branched transition states are generated; on the other hand, linear transition states are formed with hydrogen bonding with the disubstituted carbon. For this step, the most stable is branched TS1cbr which reverse to experimental facts. However, this step is predicted to be reversible and the regioselectivity is also should be controlled by the $\mathrm{H}_{2}$ oxidative addition step for the same reason as chemoselecitivy. And as shown in Figure 1, the preferred linear path is favored by $2.6 \mathrm{kcalmol}^{-1}$ thus the main hydroformylation product is linear aldehyde. These conclusions are in line with observed experimental results in the introduction.

\section{Summary}

Density functional calculations suggest that the $\mathrm{HRh}(\mathrm{CO})\left(\mathrm{PPh}_{3}\right)_{3}$ catalyzed hydroformylation of 4-(1-phenylvinyl)pyridine is exothermic.And the origin of regioselectivity is attributed to the step of substrate alkyl insertion $\mathrm{Rh}-\mathrm{H}$ bond, thus the linear aldehyde is preferred over branched aldehyde by $2.6 \mathrm{kcalmol}^{-1}$ activation free energies.

Simultaneously, the competitive hydrogenation involves vinyl addition and insertion, $\mathrm{H}_{2}$ oxidative addition which calculated to be rate-determining as well as the irreversible reductive elimination steps. And the lowest activation free energy of the rate-determining step is $13.9 \mathrm{kcalmol}^{-1}$ for hydrogenation, and $16.5 \mathrm{kcalmol}^{-1}$ for hydroformylation. Clearly, the chemoselectivity towards more hydrogenation products mentioned in introduction is clarified from the computational point.

It is noticeable that $\mathrm{CO}$ coordination is found to be an exothermic $(\Delta H<0)$, while the corresponding $\mathrm{H}_{2}$ process is endothermic $(\Delta \mathrm{H}>0), \mathrm{H}_{2}$ is not competitive with $\mathrm{CO}$ from the viewpoint of thermodynamics. But we also find that $\mathrm{CO}$ coordination is generally endergonic $(\Delta \mathrm{G}>1.2$ $\left.\mathrm{kcalmol}^{-1}\right)$ with an exception of $\mathbf{3 p n r} \rightarrow \mathbf{4 p n r}\left(\Delta \mathrm{G}=-4.6 \mathrm{kcalmol}^{-1}\right)$, so it could be conclude that the chemoselectivity of 4-(1-phenylvinyl)pyridine hydroformylation is kinetics-controlled.

\section{References}

[1] a) Airiau, E.; Girard, N.; Pizzeti, M.; Salvadori, J.; Taddei, M.; Mann, A. J. Org. Chem., 2010, 75 (24), 8670-8673; b) Lightburn, T. E.; De Paolis, O.A.; Cheng,K.H.; Tan, K. L. Org. Lett., 2011, 13 (10), 2686-2689; c) Fang, X.; Zhang, M.; Jackstell, R.; Beller,M. Angew. Chem., Int. Ed. 2013, 52(17), 4645-4649; d) Nelsen, E. R.; Landis, C. R. J. Am. Chem. Soc., 2013, 135(26), 9636-9639; e) Dydio, P.; Detz, R. J.; Reek, J. N. H. J. Am. Chem. Soc., 2013, 135(29), 10817-10828

[2] a) Zhang, X.; Cao, B.; Yu, S.; Zhang, X. Angew. Chem., Int. Ed. 2010, 49(24), 4047-4050; b) Worthy, A. D.; Joe,C. L. Lightburn, T. E.; Tan, K. L. J. Am. Chem. Soc., 2010, 132 (42), 14757-14759; c) Wang, X.; Buchwald, S. L. J. Am. Chem. Soc., 2011, 133 (47), 19080-19083; d) Chikkali, S.H.; Bellini ,R.; Bruin, B.; van der Vlugt, J.; Reek, J.N. H. J. Am. Chem. Soc., 2012, 134 (15), 6607-6616; e)Adint, T. T.; Wong, G. W.; Landis, C. R. J. Org. Chem., 2013, 78 (9), 4231-4238

[3] a) Kontkanen,M. L.; Vlasova, L.; Suvanto, S.; Haukka, M. Appl. Catal. A: General 2011, 401, 141-146; b) Kontkanen,M. L.; Haukka, M. Catal. Commun. 2012, 23, 25-29

[4] a)Botteghi, C.; Paganelli, S.; Schionato, A.; Marchetti, M. Chirality .1991, 3, 355-361; b) Kleemann, V. A. Chem. Ztg. 1977, 101, 389-394; c) Botteghi, C.; Paganelli, S.; Bigini, L.; Marchetti, M. J. Mol. Catal. 1994, 93, 279-288; d) Botteghi, C.; Marchetti, M.; Paganelli, S.; Sechi, B. J. Mol. Catal. 1997, 118, 173-179.

[5] a)Aldo, C.; Roberta, S.; Lorenzo, P.; Raffaello, L. J. Org. Chem. 2000, 599, 298-303; b) Raffaello, 
L.; Roberta, S.; Silvia, R.; Stefano, P.; Mauro, M. J. Organomet. Chem. 2005, 690, 1699-1704.

[6] a) Huo,C.F.; Li , Y.W.; Beller, M. ; Jiao, H. Organometallics, 2004, 23 (4), 765-773; b) Arribas , I.; Vargas, S.; Rubio, M.; Suárez , A.; Domene, C.; Álvarez, E.; Pizzano, A. Organometallics, 2010, 29 (22), 5791-5804; c) Takahashi, K.; Yamashita, M.; Nozaki, K. J. Am. Chem. Soc., 2012, 134 (45), 18746-18757.

[7] a) Evans, D.; Yagupsky, G.; Wilkinson, G. J. Chem. Soc. A 1968, 2660-2665; b) Evans, D.; Yagupsky, G.; Wilkinson, G. J. Chem. Soc. A 1968, 2665-2671; c) Evans, D.; Osborn, J. A.; Wilkinson, G. J. Chem. Soc. A 1968, 3133-3138

[8] a) Sparta ,M.; Børve, K.J.; Jensen, V. R. J. Am. Chem. Soc., 2007, 129 (27), 8487-8499; b) Salinas-Olvera, J. P.; Gómez, R.M.; Cortés-Guzmán, F. J. Phys. Chem. A, 2008, 112 (13), 2906-2912; c) Maeda, S.; Morokuma, K. J. Chem. Theory Comput., 2012, 8 (2), 380-385

[9] a) A. D. Becke, J. Chem. Phys. 1993, 98, 5648 -5652; b) C. Lee, W. Yang, R. G. Parr, Phys. Rev. B 1988, 37, $785-789$.

[10] a) P. J. Hay, W. R. Wadt, J. Chem. Phys. 1985, 82, 270 -283; b) W. R. Wadt, P. J. Hay, J. Chem. Phys. 1985, 82, 284 -298; c) P. J. Hay, W. R. Wadt, J. Chem. Phys. 1985, 82, 299 -310.

[11] a) Barone, V.; Cossi, M. J. Phys. Chem. A 1998, 102, 1995 -2001; b) Cossi, M. N.; Rega, G. S.; Barone, V. J. Comput. Chem. 2003, 24, $669-681$. 